\title{
An evaluation of the reproducibility of capacitive sensor based in-plane permeability measurements: A benchmarking study
}

\author{
H. Grössing ${ }^{1 *}$, D. Becker ${ }^{3}$, S. Kaufmann ${ }^{1}$, R. Schledjewski ${ }^{1,2}$, P. Mitschang ${ }^{3}$ \\ ${ }^{1}$ Christian Doppler Laboratory for High Efficient Composite Processing, Montanuniversität Leoben, Otto Glöckl-Straße 2, \\ 8700 Leoben, Austria \\ ${ }^{2}$ Chair in Processing of Composites, Department Polymer Engineering and Science, Montanuniversität Leoben, Otto \\ Glöckl-Straße 2, 8700 Leoben, Austria \\ ${ }^{3}$ Institut für Verbundwerkstoffe GmbH, Erwin-Schrödinger-Straße, Gebäude 58, 67663 Kaiserslautern, Germany
}

Received 17 July 2014; accepted in revised form 27 September 2014

\begin{abstract}
A benchmark study for permeability measurement is presented. In the past studies of other research groups which focused on the reproducibility of 1D-permeability measurements showed high standard deviations of the gained permeability values $(25 \%)$, even though a defined test rig with required specifications was used. Within this study, the reproducibility of capacitive in-plane permeability testing system measurements was benchmarked by comparing results of two research sites using this technology. The reproducibility was compared by using a glass fibre woven textile and carbon fibre non crimped fabric (NCF). These two material types were taken into consideration due to the different electrical properties of glass and carbon with respect to dielectric capacitive sensors of the permeability measurement systems. In order to determine the unsaturated permeability characteristics as function of fibre volume content the measurements were executed at three different fibre volume contents including five repetitions. It was found that the stability and reproducibility of the presented in-plane permeability measurement system is very good in the case of the glass fibre woven textiles. This is true for the comparison of the repetition measurements as well as for the comparison between the two different permeameters. These positive results were confirmed by a comparison to permeability values of the same textile gained with an older generation permeameter applying the same measurement technology.

Also it was shown, that a correct determination of the grammage and the material density are crucial for correct correlation of measured permeability values and fibre volume contents.
\end{abstract}

Keywords: polymer composites, reinforcements, processing technologies

\section{Introduction}

Liquid Composite Moulding (LCM) techniques, such as the resin transfer moulding (RTM), the vacuum assisted resin infusion (VARI) or the vacuum assisted resin transfer moulding (VARTM) process, are composite manufacturing processes which become very popular these days. Especially RTM is in the focus of interests of a variety of industries, such as aerospace, automotive, transport as well as sports and recreation, because they enable the ability to manufacture large fibre reinforced polymer composite (FRPC) parts of complex shape [1]. Even if the reproducibility of quality is comparably high and the cycle times are relatively low, these are still major issues for further process developments. One of the main advantages using RTM preforms is the opportunity to use a tailored stack of near-net shaped fibre reinforcements. Fibre preforms consist of tech-

\footnotetext{
${ }^{*}$ Corresponding author, e-mail: harald.groessing@unileoben.ac.at (C) BME-PT
} 
nical textiles, such as woven or non-crimp fabric structures, or three dimensional weaves and are constructed with glass or carbon fibres [2]. Nowadays the fibre orientation (preforming) and impregnation are two independent steps of engineering. The reinforcement used for the RTM preform are in a dry state to orientate the fibres in the load specific directions. In the next step, the preform is saturated during the RTM [3, 4]. The matrix in its liquid state, a mixture of a polymeric resin and hardener, is injected into the mould via line or point gates. The injected resin system replaces the air between and in the fibre bundles of the dry reinforcing structure [5]. An important requirement during the development of a new RTM mould is the ability to predict the flow behaviour of the resin during the mould filling phase. A number of flow variables are known which have a direct impact on the mould and process design. For components with an increased geometrical complexity those can only be realistically predicted by using a numerical filling simulation. In order to achieve the best FRP-part quality, a completely filled mould and a totally saturated preform are mandatory. In order to have a full wetted preform the position of the resin injection points and air vents must be well-placed. Currently, attempts are made to substitute the very expensive trial-and-error procedures by flow modelling tools. Numerical filling simulations support the engineers in optimizing the tool design and predicting the mould filling time. Thus, the numerical mould filling simulation tools are important and supporting tools for the advancement of the RTM process [6-10].

An accurate simulation set-up needs reliable input parameters of the time- and curing degree dependent resin viscosity, the preform porosity and the porosity-dependent preform permeability. The permeability behaviour of the textile preform is directly related to the impregnation and filling time $[7,8,11]$. The transmissibility of a porous media, in this case the fibre preform, to liquid flow is described with the term permeability. The common empirical law on fluid flow through porous media was published by Henry Darcy in 1856 [12]. Henry Darcy's law is a general accepted Equation (1) for the description of the one dimensional flow through a porous media:

$v_{\mathrm{x}}=-\frac{K_{\mathrm{x}}}{\eta} \frac{\Delta p}{\Delta x}$ where the superficial velocity of the 1D flow is $v_{\mathrm{x}}$ $[\mathrm{m} / \mathrm{s}], K_{\mathrm{x}}\left[\mathrm{m}^{2}\right]$ represents the permeability value of the measured preform direction, $\eta[\mathrm{Pa} \cdot \mathrm{s}]$ the fluid viscosity of the injected fluid and the term $\Delta p / \Delta x$ $[\mathrm{Pa} / \mathrm{m}]$ expresses the pressure drop to a specific flow length. Three different kinds of experimental methods of permeability measurements are wellknown: 1D flow [13-16], 2D flow [13, 17, 18] and 3D flow [19-22]. Nowadays no defined standard requirements for permeability measurements and calculation procedures are available [23-25]. In the study of Vernet et al. [16] there is a description of a way to standardize $1 \mathrm{D}$ permeability measurements. The main aim of this study is the comparison of two identically manufactured dielectric capacitive based in-plane permeability measurement systems located and supervised at two different research sites:

- Lehrstuhl für Verarbeitung von Verbundwerkstoffen (LVV), Leoben, Austria and the

- Institut für Verbundwerkstoffe (IVW) $\mathrm{GmbH}$, Kaiserslautern, Germany.

Despite the fact that the two systems are technically equal, there are several issues which can cause deviations between measurement results. These are:

- systematic differences between the measurement systems and their calibration - a technology sensitive to this issue is not suitable for a standardised permeability measurement

- variation concerning the usage of the possibility for manual interventions in data capturing (e.g. experiment time) and data analysis (e.g. evaluation range)

- differences during sample preparation, storage and handling

Therefore, it is the target of this study to prove that the used system allows a reproducible measurement in spite of these barriers. This proof is a main necessity for the broad acceptance of a system e.g. in serial production for material selection, process design and incoming goods control.

Two different commercially available materials which are typical for industrial customers are used for the comparison measurements. A glass fibre woven textile and a carbon fibre biaxial noncrimped fabric (NCF) are investigated. A comparison of measurements executed at both laboratories should allow an estimation, of the suitability of the measurement methodology for reproducible permeability measurement. Accordingly, the accuracy and 
the reliability of the used permeability measurement system will be examined.

\section{Review on permeability measurement techniques, benchmark studies and statistical analysis}

Literature depicts different methods and systems for permeability measurements as well as for permeability benchmark studies. Diverse references [13-18] are describing 1D and 2D measurement approaches which are able to sense the flow front as a function of time for in-plane permeability calculation. The fact that there are no standardized requirements for permeability measurement systems and no uniform calculation algorithms, permeability values measured in different research labs are differing. This is the reason why institutes and labs performed benchmark studies in the past. Also, the uncertainty of measurements and test rigs were investigated because of the stochastic and statistical influence.

\subsection{Permeability measurement techniques}

\section{$1 D$ permeability measurement}

Using 1D permeability measurement setup means that the permeability behaviour is measured in one specific direction. The saturated and unsaturated flow methods can be distinguished in order to predict the preform permeability. During the saturated 1D flow experiment a test fluid continuously flows through the fabric which is placed and compacted in a mould. The steady-state relationship between the fluid flow and the pressure drop across the whole length of the mould [26-28] is measured. For an unsaturated permeability test a dry fibre preform is used. The air which is in the fibre based material is replaced by the liquid medium [26, 28, 29] during the measurement and the flow front is tracked. A number of errors are related with this relatively simple test apparatus. First of all, there are errors, which are caused by small gaps with increased permeability between the preform edges and the mould walls which are referred to as 'Race tracking' $[2,9]$ or 'edge effect' $[30,31]$. Another disadvantage of the $1 \mathrm{D}$ test is the fact that three $1 \mathrm{D}$ measurements have to be executed for the full description of the in plane permeability tensor since three unknown variables have to be defined. The two perpendicular main directions of the flow and the orientation angle of the main directions with respect to the reference axis. Further problems arise from mould deflections and unsaturated spots [29]. The aim of an international benchmark study [16] was to eliminate the edge effects and errors by using a defined measurement method on each research lab.

\section{$2 D$ permeability measurement}

In case of an anisotropic material an ellipse occurs during commonly used centre point injection. The determination of the preform permeability values and the orientation angle of the occurring ellipse to a reference axis are still challenging problems from experimental and theoretical points of view. The knowledge about the timely flow front advancement is the most important fact for an accurate permeability calculation [32-37]. In order to calculate the permeability values of the investigated preform, the major and minor axis lengths of the occurring ellipse are needed. They are needed to determine the corresponding highest (K1) and lowest (K2) in-plane permeability values with a mathematical algorithm after having executed the permeability measurement. Adams and coworkers [32-35] and Chang and Hwang [36] are describing two different and independent algorithms for in-plane permeability calculation. Anisotropy $\alpha$ is a coefficient which describes the relationship between the major and minor axis permeability. The anisotropy coefficient is defined as the quotient of $\mathrm{K} 2$ and $\mathrm{K} 1[32,36,37]$.

For the in-plane permeability measurements different permeability test rigs are described in the literature. On the one side there are test rigs which are using sensors for flow front detection during the fluid injection. These sensors are embedded in metal mould halves $[6,17,24,29]$. On the other side there are systems with a visual aid - a camera system and a transparent upper mould half tool for flow front tracking exist $[13,38,39]$. Both show specific advantages and disadvantages. Mainly, the embedded mould sensors allow usage in a rigid steel mould which makes the system more insensitive against possible deflections. On the other side, transparent moulds allow a more exact skin flow front detection.

\subsection{Benchmark studies}

Literature depicts numerous studies for the comparison of different permeability measurement systems and methods as well as numerical error and statistical uncertainty analysis. 
In order to investigate the comparability of permeability measurements on different systems Lundström et al. [13] executed permeability measurements at three different institutes with the same magnitude of materials. In this round robin study saturated and unsaturated 1D permeability tests, as well as 2D permeability tests were performed. The results showed a good reproducibility and a standard deviation between 10 and $30 \%$ between the institutes. The unsaturated 1D flow tests showed the best repeatability in the results with a standard deviation of 8.5 respectively $15 \%$. It should also be pointed out here that the measured permeability values are increasing from the $2 \mathrm{D}$ method compared to the saturated 1D- and the 1D unsaturated flow techniques. Comparisons between the institutes and the same measurement method as well as between the 1D and 2D method showed a reproducibility of the results within the range of every single measurement method. They also obtained that there is no significant difference between saturated and unsaturated permeability. However, in a literature review performed by Dungan and Sastry [40] it was found, that the relation of saturated to unsaturated permeability can range from $1 / 4$ to 4 .

In the first international benchmark exercise Arbter et al. [41] accomplished permeability measurements on 11 institutes using 16 different measurement systems. Saturated and unsaturated 1D test rigs as well as $2 \mathrm{D}$ permeameters were used in these studies. The comparison of the results of the permeability measurements with the 16 different systems showed deviations in the range of an order of magnitude. The standard deviation of the permeability characteristics determined in this benchmark was about $1.000 \%$. Also the calculated anisotropy coefficient alternates by a factor of two between the different systems. In the second round the participants of the international benchmark study [16] used a standard RTM mould with an acrylic or a glass plate as upper mould half tool for executing the 1D permeability measurements. In order to avoid leakage during the fluid injection, a sealing rubber was positioned between the lower and upper mould half tool. The sample size was also an identified parameter that was chosen for the second measurement round. All preforms used for permeability measurements were larger than the representative elementary volume of the fabric. This was taken into account to eliminate the stochastic non-uniformity of the weaving pat- tern. Also the fibre volume content was fixed with $45 \%$. Other process parameters like the injection pressure (1 bar) and the test fluid (silicon oil) were set in order to eliminate their effect on the fluctuation on the determined data. The standard deviation of the permeability characteristics determined in second round of the international benchmark was below $25 \%$.

In both mentioned round robin studies nearly the same main sources of errors were pointed out: The accuracy of the measurement of the physical quantities, errors in cavity dimensions, changes in cavity dimensions during measurements, influences from the used liquid and the aberration of the values used for the permeability calculation algorithm. In addition the deviation of the used textile properties, the batch quality, the deviance in fibre orientation, the distance between the rovings and the differences in areal weight had an influence on the permeability calculation results. The influence of material in homogeneities are higher to assess than the experimental errors [13, 41].

\subsection{Statistical analysis}

Pan et al. [42] conducted a statistical investigation of 1D permeability measurements of woven and knitted fabrics in order to predict significant statistical influences on permeability measurements. In this study race tracking near the mould walls, variations in the areal weight and deformation effects of the measured textile using a two part tool were found to be influencing factors on the permeability. On the other side the measurement results are not affected by the experience of the executing person. Endruweit and coworkers [43-46] performed numerical and experimental analysis dealing with the deviation of geometrical parameters of technical textiles and their influencing factors on the permeability. The experimental error for their specific test case, including the estimation of parameters which are dependent on the process like injection pressure, flow front velocities, porosity and fluid viscosity, sums up to a maximum of $14 \%$. Accordingly, all variations which are above this error margin are related to the textile properties. As this is the case a unit cell based on a non-crimp fabric (NCF) was developed. Rovings with an elliptical shape were supposed and parameters for the major axis diameter (roving width) and the roving distances were considered for the variation of the geometrical 
parameters. Both factors are determining the variation of the fibre orientation angle, which increases with the decreasing quotient of roving width and roving distance. The variation of the fibre angle by using woven fabrics is assigned by available gaps between the rovings and the stitching seams by utilizing NCF's. These parameters were implemented in the numerical model and were statistically varied. Afterwards the results were compared to optical permeability measurements. The experimental results showed a trend to the normal curve of distribution and to the standard deviation of 9 to $29 \%$. The higher the ratio of roving width to the roving distances, the lower was the local permeability variation and the more similar was the real flow front shape to an ideal ellipse. With the variation of the local permeability the global permeability was decreasing too but the global permeability was decreasing with increasing ratio of roving width to roving distances. This was explained by considering the global textile. In case of high local deviations the consideration of the global textile behaviour gets more uniform due to compensational effects. The numerical developed model showed results in the same range as monitored during the experimental permeability characterization. But it has to be mentioned that effects like nesting, which are important for high roving distances and higher fibre volume contents, were not taken into account.

Fauster et al. [47] addressed their scientific work to statistical analysis of material and process parameters in order to predict the error of measurement of an optical permeameter. An analytical approach based on the law of error propagation first order as well as the Monte-Carlo simulation was used in this study. The results supply a good agreement. The considered parameters were the major and minor axis length of the occurred ellipse, the viscosity of the fluid, the injection pressure, the injection radius in the middle of the preform to eliminate the through thickness impregnation, the cavity high as well as material parameters like the fibre density and the areal weight. The supposed exactness of the measurements for the major and minor axis length of the detected ellipse were $0.1 \%$, for the fibre density $0.25 \%$ and for of the areal weight $5 \%$. The assumptions of the variance of the results were theoretically determined with $1 \%$. In addition both models calculated a variation of $8 \%$ for $\mathrm{K} 1$ and $\mathrm{K} 2$.
Due to the high standard deviations during permeability measurements Morren et al. [25] developed a solid epoxy test specimen as a reference sample for permeability measurements. The specimen was produced with a stereo lithography technique. This porous structure has the same main features as real fibre textiles. It has the same order of degree of the pore sizes and a similar interconnectivity and tortuosity of the pores. Using this test specimen for permeability measurements a standard deviation of less than $5 \%$ was reached.

In summary it can be seen that the results of permeability measurements are differing between the used permeability measurement methods (1D and 2D), but there are also inherent differences given when using the same method. This is attributed to the differences of the mechanical design and the used techniques as well as to experimental errors and variations of the textile properties. In respect to the determination of accurate and comparable permeability values and the prediction of reliable process conditions, a minimization of the material property variation, the acquisition and analysis of the special features of each single measurement system as well as the basic understanding of the geometrical variations according to the permeability characteristics are necessary. It is also very important to know, that the statistical uncertainty of material and process parameters are affecting the calculated permeability coefficients with an uncertainty of $8 \%$ [16, 41-47].

\section{Experimental set-up, materials and approach}

\subsection{Experimental set-up: 2D permeability measurement system}

The bases of the study were two similar 2D in-plane permeability measurement systems which apply capacitive sensor technology for flow front tracking. The methodology was developed and patented by the IVW [48]. The current system '2-D-CapaPerm' of the IVW states the third generation including changes in sensor positioning and number, sensor and peripheral electronics, sensor coating and data capturing and processing software. The company Präzisonsmaschinenbau Bobertag (PMB) $\mathrm{GmbH}$ built up the system for the LVV in 2013. Both systems are equal concerning the sensor arrangement. A cavity geometry of 480 by $480 \mathrm{~mm}^{2}$ is resulting due to the sensor lengths. The sensors 
are embedded in the lower mould half and the cavity high is locally not affected by the sensors. Two different sensor lengths are used. The sensor length for the east (E) and west (W) direction are $185 \mathrm{~mm}$ and the sensors for the other six directions have a length of $105 \mathrm{~mm}$. The sensitive width of all eight sensors is $5 \mathrm{~mm}$. They comprise eight actinoid positioned dielectric capacitive sensors as schematically illustrated in Figure 1.

In the upper mould a central injection point is given which results in a radial or elliptical flow, depending on the isotropy respectively anisotropy of the flow behaviour. The flow front is quasi-continuously tracked by the capacitive sensors. The dielectric properties of the inserted fibre structure inside the mould change due to increasing saturation [49]. The sensors capture the change of capacitive equivalent which represents the dielectric properties of the fibre structure lying above their sensitive area. Knowing the capacitive equivalent of the sensor when covered by dry respectively fully saturated textile, allows the derivation of the flow front position on the sensor out of the development of the sensor's capacitive equivalent over time. The correlation of flow front position and level of saturation is linear. Since eight sensors are given, at each point of experiment time, eight coordinates of the flow front are available. The elliptic equation of a perfectly point-symmetric ellipse can be defined by only three coordinates. However, if only three sensors are given, it is not possible to make a statement

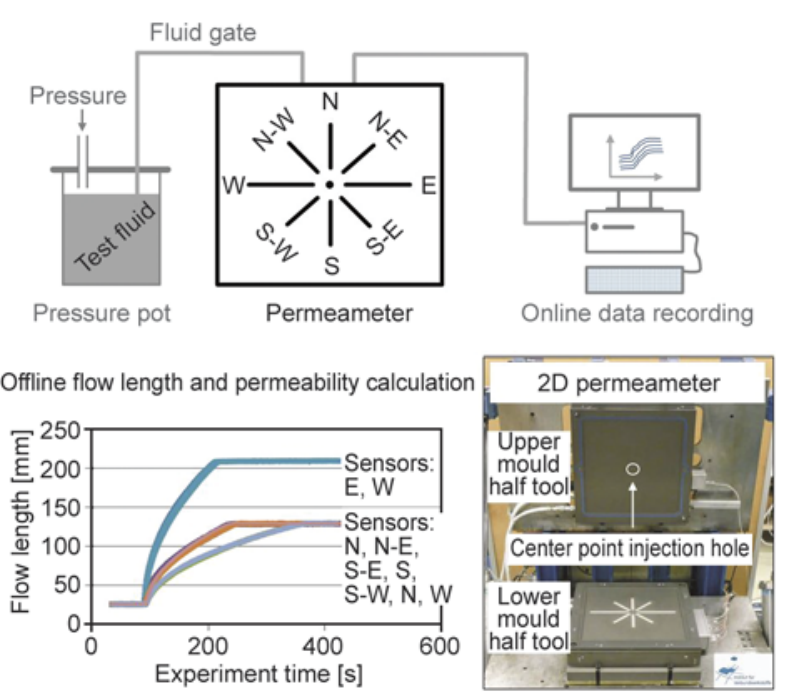

Figure 1. Schematic overview of the used sensor arrangement, the offline analysis and the permeability measurement set-up about the deviation of the true flow front from the assumption of the ideally point-symmetrical ellipse. With the eight sensors, it can be analyzed how well the assumption fits, which is also an indicator for how accurate the permeability calculation can be. Furthermore, this offers the possibility of statements on the material homogeneity, e.g. by comparing the flow front progression on opposing sensors. The 8-sensor system allows an averaging of opposing sensors which minimizes the sensitivity for local material inhomogeneities, while the information about these inhomogeneities is not lost.

Out of the elliptic equation, the calculation of length and orientation of the half-axes is possible. This is done for every time step. According to Adams et al. [34] to the fluid motion can be described by the continuity equation for incompressible flow by Equation (2) and Darcy's law in the tensorial form by Equation (3):

$\nabla \cdot v_{0}=0$

$v_{0}=-\frac{k \cdot \nabla p}{\eta}$

thereby, $v_{0}$ is the superficial velocity which is the product of flow front velocity and porosity. Correspondingly, besides the flow front movement also the pressure drop and the viscosity have to be known. Assuming the pressure at the flow front to be atmospheric the pressure drop equals the set injection pressure (gauge). The temperature-based viscosity was preliminarily measured and the fluid injection temperature is measured online. Based on this data the calculation of the permeability is possible using the methodology presented by Adams and coworkers [32-35].

Several different cavity heights between 1.45 and $8 \mathrm{~mm}$ can be realized by highly accurate steel frames. By varying the cavity height and the number of layers numerous different fibre volume contents can be set. Both measurement systems are arranged on mould carriers. A schematic representation of the permeability measurement method, the offline flow front length calculation and on the used test rig are given in Figure 1.

The software used for the calculation of the permeability out of the captured sensor data was the same at both research sites. 
Table 1. Material data of the used reinforcements for 2D permeability determination

\begin{tabular}{|l|l|l|c|}
\hline \multicolumn{1}{|c|}{ Material } & \multicolumn{1}{|c|}{ Fabric type } & Fibre material & Grammage \\
\hline Hexcel 1102 & Woven fabric, $2 / 2$ twill weave, balanced & Glass fibre & $290 \mathrm{~g} / \mathrm{m}^{2}$ \\
\hline Saertex X-C & Non crimp fabric, Biaxial, $\pm 45^{\circ}$ & Carbon fibre & $588 \mathrm{~g} / \mathrm{m}^{2}$ \\
\hline
\end{tabular}

\subsection{Materials and sample preparation}

The measurements have been executed with two dual-scale textiles differing concerning the material type, the fibre material and the grammage. Their characteristics are listed in Table 1.

In order to minimize effects of sample preparation on the results of the comparison, the preforms used for the measurement series were manufactured uniformly in one laboratory (Leoben, Austria). They were directly stacked to the intended final number of layers and cut using a CNC cutter. Subsequently, they were transferred to the IVW. The preform geometry was square shaped with an edge length of 465 by $465 \mathrm{~mm}^{2}$. In order to ensure a vertically straight flow front an injection hole of $13 \mathrm{~mm}$ diameter was cut out in the middle of the preform providing a flow channel through the thickness. Before every single measurement the preforms were weighed on a scale to evaluate the material inhomogeneity. As a test fluid rape seed oil was used. The viscosity-temperature characteristics were determined separately in each lab using an Anton Paar couette- respectively a Brookfield spindle rheometer under standardized lab conditions.

\subsection{Approach}

In order to evaluate the reproducibility of the results, the permeability at three different fibre volume contents was measured independently at both research sites. This allows the interpolation of the data based on data iteration with an exponential function, which allows a very good accordance to the actual measurement data. Thus, it was possible to use the same number of layers at both research sites, even if the cavity heights weren't exactly equal. Changing the number of layers can have an influence on the results even if the influence is small $[50,51]$.

The industry asks for reliable results which are acceptable within the repeat tests. Due to the high material costs and the measurement expenditure the measurement series should be kept to a minimum. Therefore at each fibre volume content five measurements with five preforms were performed for statistical coverage. Deviation between the single measurements gives indication about material homogeneity and measurement errors.

At first the measurement results of both institutes were directly compared, without any instruction for determination of analysis parameters. Subsequently single parameters were varied in order to estimate their influence on the reproducibility.

These parameters were:

- Time frame for permeability calculation

- Grammage of samples (individually weighed vs. averaged)

As mentioned, the permeability calculation is possible using different sensor triplets. The sensors are denoted by cardinal directions (Figure 1). Within the presented study the opposing sensors were averaged. Then the permeability was independently calculated based on the triplet $(\mathrm{N} / \mathrm{S}, \mathrm{N}-\mathrm{E} / \mathrm{S}-\mathrm{W}, \mathrm{E} / \mathrm{W})$ and $(\mathrm{N} / \mathrm{S}, \mathrm{N}-\mathrm{W} / \mathrm{S}-\mathrm{E}, \mathrm{E} / \mathrm{W})$. The resulting permeability values and orientation angles are then also averaged.

The presented work focused on the empirical determination of in-plane permeability values with two similar permeability measurement systems. The instrument errors, the error propagation as well as the human influence during sample preparation and through measurement execution were not taken into consideration.

\section{Results and discussion \\ 4.1. Independent data analysis at LVV and IVW}

Figure 2 shows the comparison of the results gained at both research sites for the glass fibre woven textiles. The time frame for analysis was independently set and the viscosity curve corresponded to the different measurement liquids used. As can be seen in the diagram of Figure 2 the data is in very good agreement. The diagram shows the permeability over the fibre volume content which corresponds to 1-porosity. Thus, increasing fibre volume content states a decreasing pore space available for flow, which decreases permeability. The minimum and maximum deviations are at 1.6 and $4.98 \%$ respectively. The chosen material perfectly suits the require- 


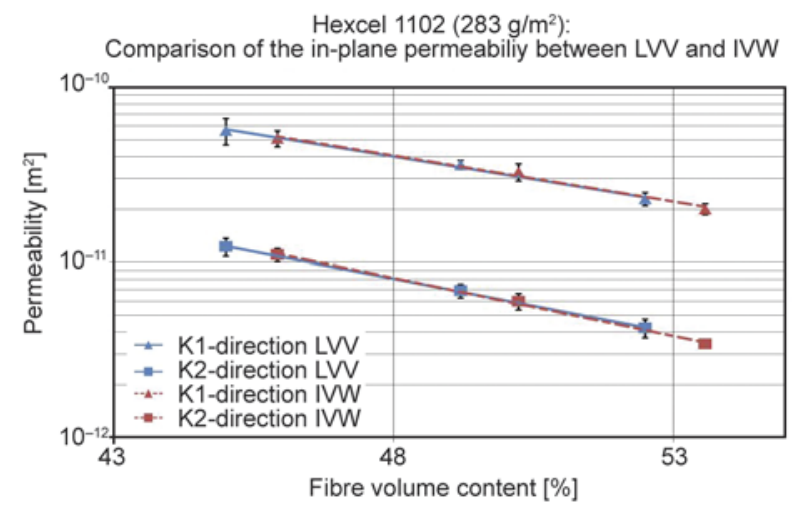

Figure 2. Comparison of the in-plane permeability values for the glass fibre woven textile independently calculated at IVW and LVV

ments for a comparison, since the variation coefficient is comparably low (between 4.52 and $17.28 \%$ ) in the light of the huge amount of materials which have been investigated at both research sites (e.g. [50]). Thus the deviation between the LVV and the IVW results is smaller than the standard deviation between the repetition measurements.

Besides the comparison between IVW and LVV the IVW results were also compared to results gained during a previous study at the institute. Rieber [50] has investigated the same material at equal cavity heights - number of layers combinations. However, it was a different batch of the material and the grammage has slightly changed in the data which results in differing fibre volume contents. Also, the system '2D-COMP' was used, which states the $2^{\text {nd }}$ generation in-plane permeameter and thus the predecessor of the currently used system. The comparison is shown in Figure 3, where again the permeability is shown over the fibre volume content. Again, the deviation between the results is smaller than the standard deviation. The similarity of the results shows the homogeneity of the chosen mate-

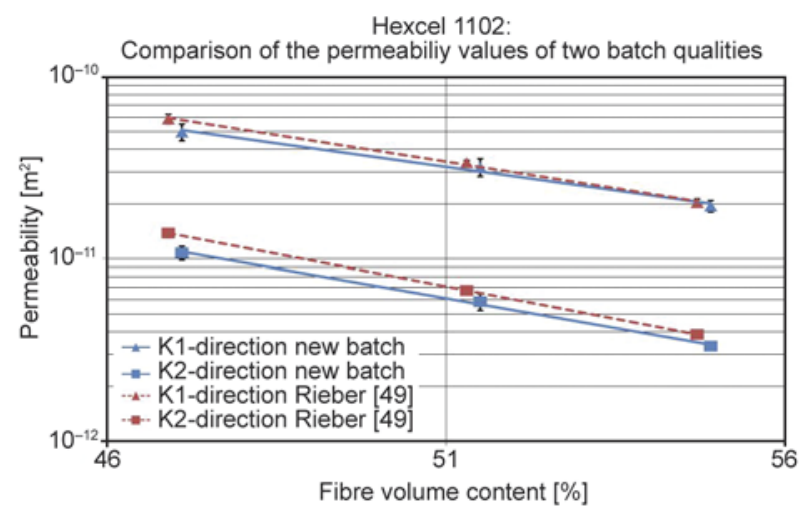

Figure 3. Comparison of IVW results with results from Rieber [50]

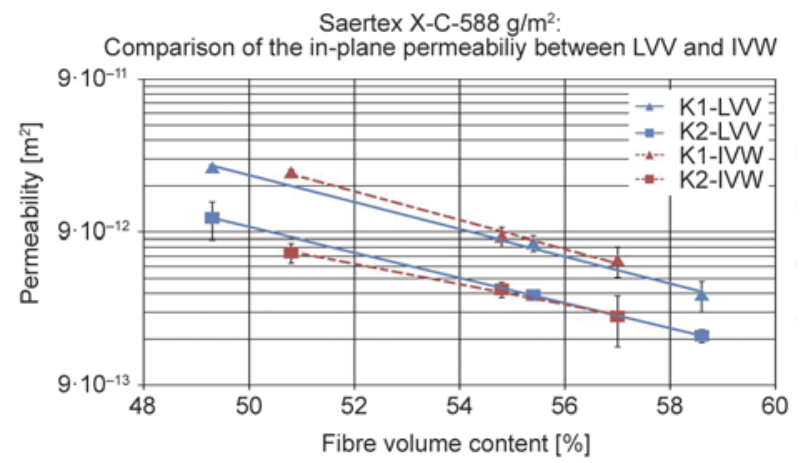

Figure 4. Comparison of the permeability values for the carbon fibre NCF independently determined at IVW and LVV

rial, but also the high reproducibility of the measurement with the capacitive technology.

The comparison of the results for the carbon fibre non-crimp fabric showed higher deviations. The results are shown in Figure 4. However, the permeability values show good accordance.

The minimum and maximum calculated standard deviations are 3.66 and $22.77 \%$ for $\mathrm{K} 1$ and 4.16 and $41.00 \%$ for K2. The comparison of both research sites showed that there is an average difference of $3.77 \%$ for the permeability of the major and $30.05 \%$ for the permeability of the minor axis. In the diagram shown in Figure 4 it can be seen that the anisotropy is higher for the IVW values, which leads to comparably higher K1-values, while the K2 values are comparably lower. Such anisotropy can be caused e.g. when during handling the crimp, which results from the differences in the weft and warp yarn tension during manufacturing, is changed. However, since only one fibre volume content is affected, no in-depth interpretation is meaningful, since the data base is rather small.

\subsection{Variation of evaluation time range}

The influence of the time range on the evaluation is an indicator for the homogeneity of the material. If the material is perfectly homogenous, it should not make an influence which time range is chosen for permeability calculation, as long as all used sensors are in a valid area (overflow started but not finished). The valid area is illustrated in Figure 5 where the metric flow data as a function of experiment time is shown for each sensor, which allows the calculation of the flow front ellipses. As can be seen, the curve growth is very homogeneous. Due to the faster velocity of the flow front advancement in the East and West direction the slopes of the curves 


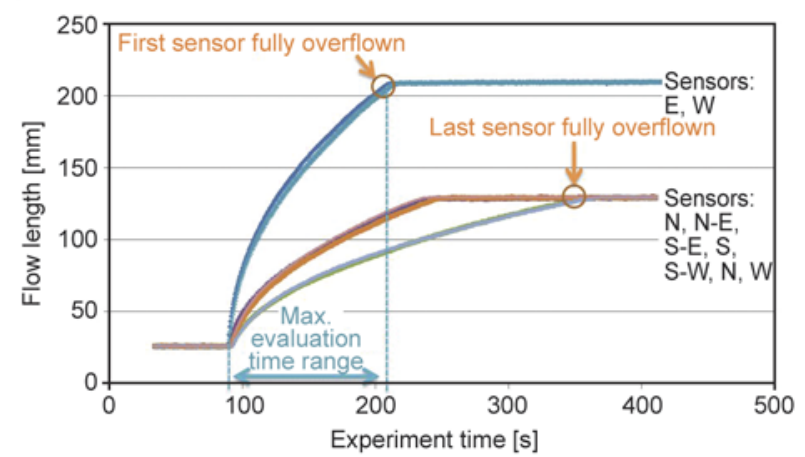

Figure 5. Flow distance over time calculated from each sensor data by using the glass fibre woven textile

have a stronger dependence on the experiment time. The flow front propagation during the permeability measurement is less dependent on the experiment time in the other six directions. That means that the anisotropy of the investigated textile is very high. Due to the fact that the sensors are located $25 \mathrm{~mm}$ away from the injection point the maximum detectable flow length increases from the sensor lengths. Thus, the maximum detectable flow lengths are an addition of the distance between the injection point to the sensitive area of the sensor and the sensitive area of the sensors itself. The maximum detectable flow lengths are $210 \mathrm{~mm}$ for the east (E) as well as the west (W) sensor and $130 \mathrm{~mm}$ for the north $(\mathrm{N})$, the south $(\mathrm{S})$, the north-east $(\mathrm{N}-\mathrm{E})$, the south-east (S-E), the south-west $(\mathrm{S}-\mathrm{W})$ and the north-west $(\mathrm{N}-\mathrm{W})$ sensors. The maximum end time for the analysis - if all sensors are taken into account - is the time point at which the first sensor is fully overflown. Using very inhomogeneous material, the curve of the flow length over the experiment time may be less smooth and show several humps. In this case the automatic detection of the status of full sensor coverage by fluid might catch the wrong hump. In this case a manual correction is possible.

In order to quantify the influence of the evaluation time range, $10 \mathrm{~s}$ were manually added to respectively subtracted from the value automatically set for end time and the permeability was recalculated. For the GF-textile, which showed even smoother curves, a change between 0.02 und $0.19 \%$ was measured for $\mathrm{K} 1$, and a change between 0.10 and $0.13 \%$ was measured for K2. The initial evaluation time range was $120 \mathrm{~s}$. For both, the glass fibre and carbon fibre textile, the time range was set individual on each research side. This reflects the measurement stability and the material homogeneity. For the CF-textile a change between -6.09 und $+5.59 \%$ was measured for $\mathrm{K} 1$, and a change between -6.96 and $6.89 \%$ was measured for K2. The initial evaluation time range was about $280 \mathrm{~s}$. Considering the results of both textiles it can be seen that a change of the evaluation time range has a higher influence on the CF-textile. The reason for this high impact can be explained with the electric properties of the $\mathrm{CF}$ and the used sensors. In some cases of measuring CF-textiles it is very difficult to determine the point on which the sensor is fully overflown because the sensor and the $\mathrm{CF}$ have an electrical interaction. This interaction at the end of the sensor can be termed as 'sensor creepage'. Thus, the sensor creepage is responsible for the higher deviation if the evaluation time range is changed as well as for the determination of the experiment end.

\subsection{Variation of grammage values}

As can be seen by the results shown in the previous sections, the influence of the fibre volume fraction on the permeability is very high. Thus, besides an accurate measurement it is also important to correlate the measured value to the right fibre volume fraction. Otherwise the exploitation of the results, e.g. for a numerical filling simulation, will be highly corrupted. Accordingly, in this section is shown, how important the correct definition and determination of the fibre volume content is. Thus their influence on the presented comparison was investigated. Three basic alternatives were examined:

1. Assume the grammage on the data sheet for each measurement

2. Measure the weight of all samples and assume all samples to have the average value

3. Directly account the measured value to the samples

Each option goes together with its advantages and disadvantages. Generally it has to be questioned where grammage deviation between the samples can arise from. Often it is caused by a fringe out at the edges of the sample. In this case it is not very meaningful to account the individual weight to each sample because the grammage in the area relevant for measurement is not affected by the fringe out. On the other side most manufacturers state a possible variation of $\pm 5 \%$ which causes huge deviation concerning the fibre volume content. Thus the first option is also not always appropriate. Therefore, the most target-aimed option seems to be to average the weight of all samples. However, knowing the indi- 
vidual weight of each sample can help to explain permeability deviations. In the case of the carbon fibre fabric the average grammage was $580.71 \mathrm{~g} / \mathrm{m}^{2}$ (min: $580,40 \mathrm{~g} / \mathrm{m}^{2}$, max: $581.07 \mathrm{~g} / \mathrm{m}^{2}$ ) while the data sheet stated $588 \mathrm{~g} / \mathrm{m}^{2}$. The resulting difference in fibre volume content can be a main error source for example for flow simulation. The permeability as a function of fibre volume content is one of the most important inputs in the flow simulation. False assumptions concerning the grammage lead to a horizontal shift of the curves. Due to the strong decreasing influence of the fibre volume content on the permeability such an error is as highly unfavourable as an error concerning the measurement itself. It can be concluded, that the influence of grammage variation on the permeability is huge. Thus, when simulating the filling process it should be taken into account that the grammage can vary (e.g. by the $5 \%$ stated in the data sheet). A possible solution would be best and worst case simulations based on the minimum and maximum permeability possible.

Grammage is only one side of the problem, when calculating the fibre respectively the pore volume fraction. Figure 6 shows the influence of the grammage on the in-plane permeability calculation.

In order to calculate the fibre volume content out of the areal weight the material density has to be known. For the glass fibre woven material the density of glass is sufficient. In the carbon fibre NCF an additional polyester stitching yarn (PSY) is present. Thus, it has to be decided which density value is to be used. The differences are exemplarily shown in Figure 7. In the first case the pore volume content was calculated taking the PSY into account but assuming it to have the same density as the carbon fibre. In the second case the individual material den-

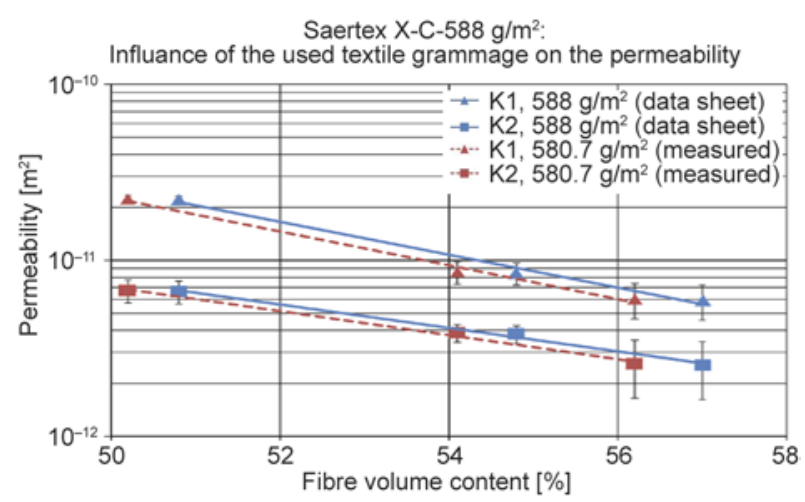

Figure 6. Influence of the used CF NCF textile grammage on the in-plane permeability values

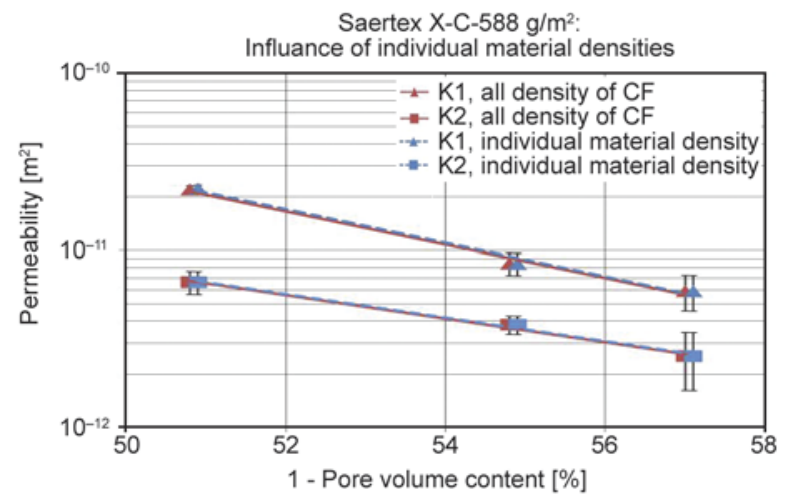

Figure 7. Influence of different approaches for grammage calculation for carbon fibre $\mathrm{NCF}$

sities were used. It would also be possible to calculate an effective material density weighted by the respective contributions to the total areal weight of the material. The resulting pore volume fraction would be the same as for the second case. The difference is about two to three percentage points. Regarding the decrease of permeability which is usually caused by such a reduction of pore space, this points out the importance of correct or at least consequent pore space calculation.

Other influencing factors on the permeability of textiles could be the filament type, the filament shape and the filament diameter. Rieber [50] showed that the influence of the filament diameter can influence the in-plane permeability values by $10 \%$ using 6 and $9 \mu \mathrm{m}$ thick filaments. Summerscales [52] refers in his work to the studies of Gurton. Gurton reports that the impregnability of a yarn with $50 \%$ fibre volume content is three times higher by using a $15 \mu \mathrm{m}$ filament diameter compared to a yarn with $5 \mu \mathrm{m}$ filament diameter.

The determined values for the permeability of the major and minor axis as well as the orientation angle are listed in Table 2 (glass fibre woven textile) and Table 3 (carbon fibre NCF). The orientation angle refers to the direction of the highest in-plane permeability $\mathrm{K} 1$ related to the production direction of the material $\left(0^{\circ}\right)$. Since both materials are not purposely sheared the permeability main axes should coincide with the material axes. Thus, the orientation angle should be $0^{\circ}$. As can be seen slight deviations from are given, which can be caused by material inhomogeneities, unintended shearing during handling, and deviations of the real flow front from the assumed ideally point-symmetrical ellipse. Considering the orientation angle detected at the IVW for the CF NCF at a FVC of $54.80 \%$ it can be seen that 
Table 2. Major and minor axis permeability values for the glass fibre woven textile

\begin{tabular}{|l|c|c|c|c|c|c|c|}
\hline \multirow{3}{*}{ Laboratory } & \multirow{2}{*}{$\begin{array}{c}\text { FVC } \\
{[\%]}\end{array}$} & $\begin{array}{c}\text { Average } \\
{\left[\mathbf{m}^{\mathbf{2}}\right]}\end{array}$ & $\begin{array}{c}\text { Deviation } \\
{[\%]}\end{array}$ & $\begin{array}{c}\text { Average } \\
{\left[\mathbf{m}^{2}\right]}\end{array}$ & $\begin{array}{c}\text { Keviation } \\
{[\%]}\end{array}$ & $\begin{array}{c}\text { Overage } \\
{[\%]}\end{array}$ & $\begin{array}{c}\text { Oeviation } \\
{\left[{ }^{\circ}\right]}\end{array}$ \\
\cline { 2 - 8 } & 46.10 & $5.53 \cdot 10^{-11}$ & 17.28 & $1.20 \cdot 10^{-11}$ & 11.70 & 1.40 & \pm 2.54 \\
\hline \multirow{3}{*}{ LVV } & 50.40 & $3.51 \cdot 10^{-11}$ & 5.95 & $6.73 \cdot 10^{-12}$ & 8.85 & 0.80 & \pm 2.16 \\
\cline { 2 - 9 } & 53.80 & $2.97 \cdot 10^{-11}$ & 8.63 & $5.48 \cdot 10^{-12}$ & 12.13 & 1.40 & \pm 1.45 \\
\hline \multirow{3}{*}{ IVW } & 47.10 & $4.98 \cdot 10^{-11}$ & 10,60 & $1,08 \cdot 10^{-11}$ & 8.68 & 0.96 & \pm 1.13 \\
\cline { 2 - 8 } & 51.50 & $3.19 \cdot 10^{-11}$ & 11.20 & $5.85 \cdot 10^{-12}$ & 10.62 & 0.04 & \pm 0.63 \\
\cline { 2 - 8 } & 54.90 & $1.95 \cdot 10^{-11}$ & 7.20 & $3.33 \cdot 10^{-12}$ & 4.52 & 1.08 & \pm 0.92 \\
\hline
\end{tabular}

Table 3. Major and minor axis permeability values for the carbon fibre NCF

\begin{tabular}{|l|c|c|c|c|c|c|c|}
\hline \multirow{3}{*}{ Laboratory } & \multirow{2}{*}{$\begin{array}{c}\text { FVC } \\
{[\%]}\end{array}$} & $\begin{array}{c}\text { Average } \\
{\left[\mathbf{m}^{\mathbf{2}}\right]}\end{array}$ & $\begin{array}{c}\text { Deviation } \\
{[\%]}\end{array}$ & $\begin{array}{c}\text { Average } \\
{\left[\mathbf{m}^{2}\right]}\end{array}$ & $\begin{array}{c}\text { Deviation } \\
{[\%]}\end{array}$ & $\begin{array}{c}\text { Average } \\
{\left[{ }^{\circ}\right]}\end{array}$ & $\begin{array}{c}\text { Orientation angle } \\
\text { Deviation } \\
{\left[{ }^{\circ}\right]}\end{array}$ \\
\hline \multirow{3}{*}{ LVV } & 49.30 & $2.37 \cdot 10^{-11}$ & 3.66 & $1.11 \cdot 10^{-11}$ & 27.61 & 3.06 & \pm 1.59 \\
\cline { 2 - 9 } & 55.40 & $7.62 \cdot 10^{-12}$ & 11.64 & $3.49 \cdot 10^{-12}$ & 4.61 & 3.83 & \pm 3.83 \\
\cline { 2 - 9 } & 58.60 & $3.50 \cdot 10^{-12}$ & 22.77 & $1.89 \cdot 10^{-12}$ & 9.83 & 7.09 & \pm 7.53 \\
\hline \multirow{3}{*}{ IVW } & 50.80 & $2.20 \cdot 10^{-11}$ & 4.97 & $6.64 \cdot 10^{-12}$ & 14.87 & 0.02 & \pm 7.40 \\
\cline { 2 - 9 } & 54.80 & $8.43 \cdot 10^{-12}$ & 14.51 & $3.81 \cdot 10^{-12}$ & 11.69 & -3.19 & \pm 6.32 \\
\cline { 2 - 9 } & 57.00 & $5.90 \cdot 10^{-12}$ & 22.73 & $2.28 \cdot 10^{-12}$ & 40.97 & 3.53 & \pm 10.80 \\
\hline
\end{tabular}

this value is negative. Due to the large preform size which gets saturated during the measurement, material inhomogeneity and handling as well as shearing effects it is possible to generate a negative value for the orientation angle.

\section{Conclusions}

In this study two similar dielectric capacitive based 2D permeability measurement systems were compared by measuring two different materials. A glass fibre woven textile and a carbon fibre based biaxial $\mathrm{NCF}$ were investigated at two diverse research sites. In order to eliminate the influence of sample preparation the samples were prepared in Leoben, Austria and were shipped to Kaiserslautern, Germany. The permeability measurements were executed independently of each site. The permeability results and the reproducibility of these chosen textiles gained at the two research labs are valid for the investigated material. The reproducibility and the accuracy of the permeability measurements cannot be transferred to other textiles produced with other materials, e.g. aramid or natural fibres.

The results can be summarized and are stating to the following:

- The results for the in-plane permeability values have shown a very good agreement. The deviance between the LVV and the IVW results is smaller than the standard deviation between the repetition measurements.
- A high reproducibility of permeability measurements was also reached by comparing two batch qualities to each other. The similarity of the results shows the homogeneity of the chosen material. Also the older batch was measured with a third capacity technology-based system.

- The comparison of the permeability results of the carbon fibre NCF showed higher deviations but there is also a good agreement between the two research sites.

- The in-plane permeability values are affected by the used textile grammage. The grammage is directly related to the fibre volume content which influences on the permeability calculation.

- In the case of the carbon fibre textile an additional polyester stitching yarn is present. If the carbon fibre and the polyester yarn were allocated with their true density the difference of the calculated permeabilities were two to three percentages compared to the procedure of using only the density of a carbon fibre.

It could be shown that the dielectric capacitive permeameter technology is a promising approach towards reliable and reproducible permeability measurements. The executed radial in-plane measurements show a low standard deviation and a very good reproducibility in the case of the glass fibre woven textile. It can also be noted that by using the presented technology it is possible to measure the same permeability characteristics with a very low 
deviation in two different located and supervised labs.

\section{Acknowledgements}

The authors kindly acknowledge the financial support provided by both the Bundesministerium für Wirtschaft, Familie und Jugend in Austria, the Christian Doppler Laboratory and the FACC Operations GmbH.

The authors also kindly acknowledge the funding of the project 'Westaperm - Advancement and Extension of the 2D-Measurement cell for the standardized determination of the permeability of textile fibre structures' by AIF within the ZIM-program.

\section{References}

[1] Lässig R., Eisenhut M., Mathias A., Schulte R. T., Peters F., Kühmann T., Waldmann T., Begemann W.: Serienproduktion von hochfesten Faserverbundbauteilen. Perspektiven für den deutschen Maschinen-und Anlagenbau. Studie von Roland Berger Consultants (2012).

[2] Bickerton S., Advani S. G.: Characterization and modeling of race-tracking in liquidcomposite molding processes. Composites Science and Technology, 59, 2215-2229 (1999).

DOI: 10.1016/S0266-3538(99)00077-9

[3] Weimer C., Preller T., Mitschang P., Drechsler K.: Approach to net-shape preforming using textile technologies. Part I: Edges. Composites Part A: Applied Science and Manufacturing, 31, 1261-1268 (2000).

DOI: $10.1016 / \mathrm{S} 1359-835 \mathrm{X}(00) 00073-7$

[4] Weimer C., Preller T., Mitschang P., Drechsler K.: Approach to net-shape preforming using textile technologies. Part II: Holes. Composites Part A: Applied Science and Manufacturing, 31, 1269-1277 (2000). DOI: $10.1016 / \mathrm{S} 1359-835 \mathrm{X}(00) 00074-9$

[5] Kendall K. N., Rudd C. D., Owen M. J., Middleton V.: Characterization of the resin transfer moulding process. Composites Manufacturing, 3, 235-249 (1992). DOI: 10.1016/0956-7143(92)90111-7

[6] Rieber G., Jiang J., Deter C., Chen N., Mitschang P.: Influence of textile parameters on the in-plane permeability. Composites Part A: Applied Science and Manufacturing, 52, 89-98 (2013).

DOI: 10.1016/j.compositesa.2013.05.009

[7] Verleye B., Croce R., Griebel M., Klitz M., Lomov S. V., Morren G., Sol H., Verpoest I., Roose D.: Permeability of textile reinforcements: Simulation, influence of shear and validation. Composites Science and Technology, 68, 2804-2810 (2008).

DOI: $10.1016 /$ j.compscitech.2008.06.010

[8] Liu X-L.: Isothermal flow simulation of liquid composite molding. Composites Part A: Applied Science and Manufacturing, 31, 1295-1302 (2000).

DOI: $10.1016 / \mathrm{S} 1359-835 \mathrm{X}(00) 00007-5$
[9] Steenkamer D. A., Wilkins D. J., Karbhari V. M.: The influence of preform joints on the processing of RTM composites. Composites Manufacturing, 6, 23-34 (1995). DOI: $10.1016 / 0956-7143(95) 93710-2$

[10] Louis M., Huber U.: Investigation of shearing effects on the permeability of woven fabrics and implementation into LCM simulation. Composites Science and Technology, 63, 2081-2088 (2003). DOI: $10.1016 / \mathrm{S} 0266-3538(03) 00111-8$

[11] Grujicic M., Chittajallu K. M., Walsh S.: Non-isothermal preform infiltration during the vacuum-assisted resin transfer molding (VARTM) process. Applied Surface Science, 245, 51-64 (2005).

DOI: $10.1016 / \mathrm{j}$. apsusc. 2004.09 .123

[12] Darcy H.: Les fontaines publiques de la ville de Dijon. Victor Dalmont, Paris (1856).

[13] Lundström T. S., Stenberg R., Bergström R., Partanen H., Birkeland P. A.: In-plane permeability measurements: A nordic round-robin study. Composites Part A: Applied Science and Manufacturing, 31, 29-43 (2000). DOI: 10.1016/S1359-835X(99)00058-5

[14] Amico S., Lekakou C.: An experimental study of the permeability and capillary pressure in resin-transfer moulding. Composites Science and Technology, 61, 1945-1959 (2001). DOI: $10.1016 / \mathrm{S} 0266-3538(01) 00104-\mathrm{X}$

[15] Gebart B. R., Lidström P.: Measurement of in-plane permeability of anisotropic fiber reinforcements. Polymer Composites, 17, 43-51 (1996).

DOI: $10.1002 / p c .10589$

[16] Vernet N., Ruiz E., Advani S., Alms J. B., Aubert M., Barburski M., Barari B., Beraud J. M., Berg D. C., Correia N., Danzi M., Delavière T., Dickert M., Di Fratta C., Endruweit A., Ermanni P., Francucci G., Garcia J. A., George A., Hahn C., Klunker F., Lomov S. V., Long A., Louis B., Maldonado J., Meier R., Michaud V., Perrin H., Pillai K., Rodriguez E., Trochu F., Verheyden S., Wietgrefe M., Xiong W., Zaremba S., Ziegmann G.: Experimental determination of the permeability of engineering textiles: Benchmark II. Composites Part A: Applied Science and Manufacturing, 61, 172-184 (2014).

DOI: $10.1016 /$ j.compositesa.2014.02.010

[17] Hoes K., Dinescu D., Sol H., Vanheule M., Parnas R. S., Luo Y., Verpoest I.: New set-up for measurement of permeability properties of fibrous reinforcements for RTM. Composites Part A: Applied Science and Manufacturing, 33, 959-969 (2002). DOI: $10.1016 / \mathrm{S} 1359-835 \mathrm{X}(02) 00035-0$

[18] Rieber G., Mitschang P.: 2D permeability changes due to stitching seams. Composites Part A: Applied Science and Manufacturing, 41, 2-7 (2010). DOI: 10.1016/j.compositesa.2009.09.006 
[19] Weitzenböck J. R., Shenoi R. A., Wilson P. A.: Measurement of three-dimensional permeability. Composites Part A: Applied Science and Manufacturing, 29, 159-169 (1998). DOI: $10.1016 /$ S1359-835X(97)00049-3

[20] Nedanov P. B., Advani S. G.: A method to determine 3D permeability of fibrous reinforcements. Journal of Composite Materials, 36, 241-254 (2002).

DOI: $10.1177 / 0021998302036002462$

[21] Okonkwo K., Simacek P., Advani S. G., Parnas R. S.: Characterization of 3D fiber preform permeability tensor in radial flow using an inverse algorithm based on sensors and simulation. Composites Part A: Applied Science and Manufacturing, 42, 1283-1292 (2011). DOI: 10.1016/j.compositesa.2011.05.010

[22] Stöven T., Weyrauch F., Mitschang P., Neitzel M.: Continuous monitoring of three-dimensional resin flow through a fibre preform. Composites Part A: Applied Science and Manufacturing, 34, 475-480 (2003). DOI: $10.1016 / \mathrm{S} 1359-835 \mathrm{X}(03) 00059-9$

[23] Valdes-Parada F. J., Ochoa-Tapia J. A., Alvarez-Ramirez J.: Validity of the permeability Carman-Kozeny equation: A volume averaging approach. Physica A: Statistical Mechanics and its Applications, 388, 789798 (2009).

DOI: $10.1016 /$ j.physa.2008.11.024

[24] Morren G., Bossuyt S., Sol H.: 2D permeability tensor identification of fibrous reinforcements for RTM using an inverse method. Composites Part A: Applied Science and Manufacturing, 39, 1530-1536 (2008). DOI: $10.1016 /$ j.compositesa.2008.05.019

[25] Morren G., Bottiglieri M., Bossuyt S., Sol H., Lecompte D., Verleye B., Lomov S. V.: A reference specimen for permeability measurements of fibrous reinforcements for RTM. Composites Part A: Applied Science and Manufacturing, 40, 244-250 (2009). DOI: $10.1016 / \mathrm{j}$. compositesa.2008.11.011

[26] Hammond V. H., Loos A. C.: The effects of fluid type and viscosity on the steady-state and advancing front permeability behavior of textile preforms. Journal of Reinforced Plastics and Composites, 16, 50-72 (1997). DOI: $10.1177 / 073168449701600105$

[27] Parnas R. S., Salem A. J.: A comparison of the unidirectional and radial in-plane flow of fluids through woven composite reinforcements. Polymer Composites, 14, 383-394 (1993).

DOI: $10.1002 /$ pc. 750140504

[28] Francucci G., Rodríguez E. S., Vázquez A.: Study of saturated and unsaturated permeability in natural fiber fabrics. Composites Part A: Applied Science and Manufacturing, 41, 16-21 (2010).

DOI: $10.1016 /$ j.compositesa.2009.07.012

[29] Liu Q., Parnas R. S., Giffard H. S.: New set-up for inplane permeability measurement. Composites Part A: Applied Science and Manufacturing, 38, 954-962 (2007).

DOI: $10.1016 /$ j.compositesa.2006.06.024
[30] Bickerton S., Sozer E. M., Graham P. J., Advani S. G.: Fabric structure and mold curvature effects on preform permeability and mold filling in the RTM process. Part I. Experiments. Composites Part A: Applied Science and Manufacturing, 31, 423-438 (2000). DOI: 10.1016/S1359-835X(99)00087-1

[31] Bickerton S., Sozer E. M., Šimácek P., Advani S. G.: Fabric structure and mold curvature effects on preform permeability and mold filling in the RTM process. Part II. Predictions and comparisons with experiments. Composites Part A: Applied Science and Manufacturing, 31, 439-458 (2000).

DOI: $10.1016 / \mathrm{S} 1359-835 \mathrm{X}(99) 00088-3$

[32] Adams K. L., Rebenfeld L.: In-plane flow of fluids in fabrics: Structure/flow characterization. Textile Research Journal, 57, 647-654 (1987). DOI: $10.1177 / 004051758705701104$

[33] Adams K. L., Rebenfeld L.: Permeability characteristics of multilayer fiber reinforcements. Part II: Theoretical model. Polymer Composites, 12, 186-190 (1991). DOI: $10.1002 / p c .750120308$

[34] Adams K. L., Russel W. B., Rebenfeld L.: Radial penetration of a viscous liquid into a planar anisotropic porous medium. International Journal of Multiphase Flow, 14, 203-215 (1988). DOI: $10.1016 / 0301-9322(88) 90006-7$

[35] Adams K. L., Rebenfeld L.: Permeability characteristics of multilayer fiber reinforcements. Part I: Experimental observations. Polymer Composites, 12, 179185 (1991).

DOI: $10.1002 /$ pc. 750120307

[36] Chan A. W., Hwang S-T.: Anisotropic in-plane permeability of fabric media. Polymer Engineering and Sciene, 31, 1233-1239 (1991). DOI: $10.1002 /$ pen.760311613

[37] Weitzenböck J. R., Shenoi R. A., Wilson P. A.: Radial flow permeability measurement. Part A: Theory. Composites Part A: Applied Science and Manufacturing, 30, 781-796 (1999). DOI: $10.1016 / \mathrm{S} 1359-835 \mathrm{X}(98) 00183-3$

[38] Schledjewski R., Grössing H., Fauster E.: Accurate 2D permeability measurement: Optical permeability characterisation. in: 'SAMPE SETEC 2013: Novel aspects in composite technologies: From fibre to light weight structures. Wuppertal, Germany' 34-40 (2013).

[39] Stadtfeld H. C.: Entwicklung einer Messzelle zur Bestimmung von Kompaktierungs- und Permeabilitätskennwerten bei flächigen Faserhalbzeugen. PhD thesis, Technische Universität Kaiserslautern, Kaiserslautern (2006).

[40] Dungan F. D., Sastry A. M.: Saturated and unsaturated polymer flows: Microphenomena and modeling. Journal of Composite Materials, 36, 1581-1603 (2002). DOI: $10.1177 / 0021998302036013179$ 
[41] Arbter R., Beraud J. M., Binetruy C., Bizet L., Bréard J., Comas-Cardona S., Demaria C., Endruwei A., Ermanni P., Gommer F., Hasanovic S., Henrat P., Klunker F., Laine B., Lavanchy S., Lomov S. V., Long A., Michaud V., Morren G., Ruiz E., Sol H., Trochu F., Verleye B., Wietgrefe M., Wu W., Ziegmann G.: Experimental determination of the permeability of textiles: A benchmark exercise. Composites Part A: Applied Science and Manufacturing, 42, 1157-1168 (2011).

DOI: $10.1016 /$ j.compositesa.2011.04.021

[42] Pan R., Liang Z., Zhang C., Wang B.: Statistical characterization of fiber permeability for composite manufacturing. Polymer Composites, 21, 996-1006 (2000). DOI: $10.1002 / p c .10253$

[43] Endruweit A., Long A. C.: Influence of stochastic variations in the fibre spacing on the permeability of bidirectional textile fabrics. Composites Part A: Applied Science and Manufacturing, 37, 679-694 (2006). DOI: 10.1016/j.compositesa.2005.08.003

[44] Endruweit A., Long A. C., Robitaille F., Rudd C. D.: Influence of stochastic fibre angle variations on the permeability of bi-directional textile fabrics. Composites Part A: Applied Science and Manufacturing, 37, 122-132 (2006).

DOI: 10.1016/j.compositesa.2005.04.014

[45] Endruweit A., McGregor P., Long A. C., Johnson M. S.: Influence of the fabric architecture on the variations in experimentally determined in-plane permeability values. Composites Science and Technology, 66, 1778-1792 (2006).

DOI: $\underline{10.1016 / \text { j.compscitech.2005.10.031 }}$
[46] Endruweit A., Gommer F., Long A. C.: Stochastic analysis of fibre volume fraction and permeability in fibre bundles with random filament arrangement. Composites Part A: Applied Science and Manufacturing, 49, 109-118 (2013). DOI: 10.1016/j.compositesa.2013.02.012

[47] Fauster E., Grössing H., Schledjewski R.: Uncertainty analysis for optical permeability measurement of reinforceding textiles. in: 'Proceedings of ICCM 19, Montreal, Canada' 5802-5809 (2013).

[48] Daniel P., Kissinger C., Roeder G.: Anordnung zur Vermessung der Ausbreitung eines Matrixmaterials in elektrisch leitfähigen Verstärkungsstrukturen. DE 10004146 C2, Germany (2000).

[49] Kissinger C., Mitschang P., Neitzel M., Roeder G., Haberland R.: Continuous on-line permeability measurement of textile structures. in: 'Proceedings of the $45^{\text {th }}$ International SAMPE Symposium and Exhibition, Long Beach, California, USA', 2089-2096 (2000).

[50] Rieber G.: Einfluss von textilen Parametern auf die Permeabilität von Multifilamentgeweben für Faserverbundkunststoffe. PhD thesis, Technische Universität Kaiserslautern, Kaiserslautern (2011).

[51] Lekakou C., Johari M. A. K. B., Bader M. G.: Compressibility and flow permeability of two-dimensional woven reinforcements in the processing of composites. Polymer Composites, 17, 666-672 (1996). DOI: $10.1002 / p c .10658$

[52] Summerscales J.: A model for the effect of fibre clustering on the flow rate in resin transfer moulding. Composites Manufacturing, 4, 27-31 (1993). DOI: $10.1016 / 0956-7143(93) 90013-\mathrm{X}$ 